\title{
Is HIV/AIDS challenging among high school students in Rasht, Iran? A descriptive-analytical study
}

\author{
Lida Mahfoozi ${ }^{1}$, Aydin Pourkazemi ${ }^{1}, Z^{2}$ hra Atrkarroushan ${ }^{2}$, Rena Ghaffari ${ }^{3}$, Tofigh Yaghubi Kalurazi ${ }^{1}$ \\ ${ }^{1}$ Department of Health, Nutrition and Infectious Diseases, School of Medicine, Guilan University of Medical Sciences, Rasht, Iran \\ ${ }^{2}$ Department of Community Medicine, School of Medicine, Social Determinants of Health Research Center, Guilan University \\ of Medical Sciences, Rasht, Iran \\ ${ }^{3}$ Guilan University of Medical Sciences, Rasht, Iran
}

\begin{abstract}
Introduction: Acquired immunodeficiency syndrome (AIDS) is one of the most serious health problems and one of the deadliest communicable infectious diseases of this century. Increasing knowledge and changing wrong beliefs and behaviors is the best way to prevent this disease. The purpose of this study was to determine the knowledge and attitude of high school students about AIDS.

Material and methods: This descriptive-analytical study was performed on 500 high school students at secondary high school level in experimental field in Rasht City. At first, some schools were randomly selected as clusters and then, the required samples from each school were selected by systematic random sampling. The research tool used in this study was a questionnaire consisting of three sections: general information, knowledge assessment, and attitude assessment. The data were entered into SPSS software and analyzed using $\chi^{2}$ test.

Results: In terms of knowledge level, 347 (69.4\%) students had sufficient knowledge, 142 (28.4\%) presented medium, and $11(2.2 \%)$ insufficient level of AIDS knowledge. In terms of attitude level, $354(70.8 \%)$ had positive attitude, 145 (29\%) had neutral attitude, and $1(0.2 \%)$ had negative attitude. There was a statistically significant difference between the level of knowledge of students with gender, educational grade, and school type ( $p=0.0001)$.

Conclusions: The results of this study indicate the necessity of continuation of formal and informal education, and efforts of educational, health, and cultural officials in order to teach AIDS control and prevention methods.
\end{abstract}

HIV AIDS Rev 2020; 19, 4: 273-277

DOI: https://doi.org/10.5114/hivar.2020.101747

Key words: AIDS, HIV AIDS knowledge, attitude, students with HIV, Rasht City.

\section{Introduction}

Acquired immunodeficiency syndrome (AIDS) is one of the most serious health problems and one of the deadliest communicable infectious disease of the present century [1]. The emergence of AIDS and lack of knowledge on the dis-

ease can easily put adolescents at risk. It often infects people at the age of onset of sexual activity, which coincides with the onset of adolescence $[2,3]$. The World Health Organization announced in 2010 that the number of people with the disease in developing countries was up to five times

Article history:

Received: 11.11.2019

Received in revised form: 04.03.2020

Accepted: 27.05.2020

Available online: 30.11 .2020
International Journal of HIV-Related Problems

HIV \& AIDS

R e v i e w 
higher than those recorded [3]. In some countries, for cultural or religious reasons, young girls and women tend to maintain their virginity before marriage, and sometimes, they initiate the types of sexual intercourse that are associated with a higher risk of human immunodeficiency virus (HIV) transmission. On the other hand, there are street children, who sometimes practice prostitution for shelter or food, or they get raped due to lack of parents. Therefore, the prevalence of HIV infection in this group is also high [4].

There is currently no specific cure or vaccine to prevent the disease. New therapies and antiretroviral drugs only prolong the life of patients [5]. AIDS is considered as a disgraceful disease in Iran, which causes the patient to be rejected by the society and family. Thus, AIDS causes isolation, depression, humiliation, and suicide in the affected group [6]. Adolescents are at risk for AIDS because of lack of access to information on the disease, prevention methods, and risky sexual behaviors. Education and promotion the awareness of at-risk people is of high importance $[7,8]$. The trend of the disease has decreased in European and American countries due to education and awareness programs, but it is progressing in Asian countries.

According to experts, since HIV transmission occurs mostly through sexual contact with an infected person, contaminated blood and blood products, and needles and syringes, raising people's awareness on HIV/AIDS can greatly help in reducing the growing rate of AIDS [9]. As studies show, misconceptions and lack of awareness on this disease are very common among adolescents, and it is clear that good quality education for all children and adolescents is essential in the fight against this epidemic to save lives that are endangered by ignorance and fear of the disease[10]. The important point is that although schools have a fundamental commitment to implement and develop adolescent AIDS prevention/intervention programs, the fears of many Iranians who believe that AIDS education increases risky behaviors, have caused sex education on HIV/AIDS transmission not taken seriously in schools and universities. Therefore, it is necessary to recognize the knowledge, beliefs, and even common misconceptions among people, especially this group of adolescents on AIDS.

\section{Material and methods}

\section{Study design and population}

The present study is a descriptive-analytical study, and it was conducted in two parts: knowledge assessment was done with a descriptive-analytical method, and attitude assessment was completed using a descriptive method. The statistical population was high school students in Rasht. In this study, two-stage random sampling method was used.

\section{Study tools}

A questionnaire was used in this study. Students were explained that an incorrect answer in the questionnaire had no negative score. Respondents were not restricted to complete the questionnaire during one session. After completing the questionnaire, each respondent was provided with an answer sheet containing correct answers. The research questionnaire consisted of 31 questions in three parts. In Mazloomi et al. study, the validity of this questionnaire was verified and validated by several experts in the field of infectious diseases and health education [3]. Cronbach's $\alpha$ index was applied to measure its reliability and to confirm the internal consistency of the questionnaire. The reliability of the questionnaire was calculated as 0.80 by Cronbach's $\alpha$. The first part of the questionnaire was on students' general and demographic information, such as gender, parental education, parental occupation, educational background, and school type. The second part was about the students' awareness, which consisted of 20 questions. The students' answers to the questions were "yes" or "no". A correct answer to question had a 1 score and no answer or wrong answer had a 0 score. Zero to 10 was considered as insufficient knowledge, $11-15$ as medium, and $16-20$ as sufficient. The third part of the questionnaire was assessing students' attitude. The scoring method was based on a 5-point Likert scale, including "strongly disagree" (score 1), "disagree" (score 2), "neutral" (score 3), "agree" (score 4), and "strongly agree" (score 5). However, this method of scoring was reversed for questions $2,3,5,6,7,8,9,10$, and 11 . To obtain the overall score of the questionnaire, the sum of scores for all questions was calculated. The score ranged from 11 to 55 . A score between 11 and 25 was considered as negative (undesirable) attitude, score 26-40 as neutral attitude, and score 41-55 was deemed positive (desirable) attitude. The sample size was estimated as 500 responders [11].

In this research, participants were not subjected to any harm in any way, whatsoever. Respect for the dignity of participants was prioritized. Full consent was obtained from the responders prior to the study. The protection of participants privacy was ensured. An adequate level of confidentiality of the research data was confirmed. Anonymity of individuals and organizations participating in the research was also confirmed. In the current study, any deception or exaggeration about the aims and objectives of the research was avoided.

\section{Statistical analysis}

After data collection, the information were entered into SPSS software version 16 , and $\chi^{2}$ test was used to investigate the significant relationship between the data and variables studied. The significance level of tests in this study with $p<0.05$ was considered as two-way and statistical significance.

\section{Results}

In this study, a total of 500 students from the secondary level of high school in the experimental field were investigated. The frequency and percentage of students' gender, age, parents' education, parents' occupation, type of school, level of knowl- 
Table 1. Frequency of demographic findings in the subjects

\begin{tabular}{|c|c|c|}
\hline Variable & Frequency & Percentage \\
\hline \multicolumn{3}{|l|}{ Gender } \\
\hline Male & 186 & $2 / 37$ \\
\hline Female & 314 & $8 / 62$ \\
\hline Total & 500 & 100 \\
\hline \multicolumn{3}{|l|}{ Age } \\
\hline 15 & 93 & $6 / 18$ \\
\hline 16 & 237 & $4 / 47$ \\
\hline 17 & 159 & $8 / 31$ \\
\hline 18 & 11 & $2 / 2$ \\
\hline Total & 500 & 100 \\
\hline \multicolumn{3}{|l|}{ Father's education } \\
\hline Undergraduate education & 24 & $8 / 4$ \\
\hline Diploma & 99 & $8 / 19$ \\
\hline Associate degree & 45 & 9 \\
\hline Bachelors' degree & 159 & $8 / 31$ \\
\hline Higher education & 173 & $6 / 34$ \\
\hline Total & 500 & 100 \\
\hline \multicolumn{3}{|l|}{ Mother's education } \\
\hline Undergraduate education & 15 & 3 \\
\hline Diploma & 121 & $2 / 24$ \\
\hline Associate degree & 48 & $6 / 9$ \\
\hline Bachelors' degree & 201 & $2 / 40$ \\
\hline Higher education & 115 & 23 \\
\hline Total & 500 & 100 \\
\hline
\end{tabular}

edge, and attitude about AIDS are shown in Table 1. According to Table 2, there was a statistically significant difference between the level of students' knowledge and gender $(p=0.0001)$. The frequency of people with sufficient knowledge on AIDS was significantly higher in male students than females (Table 2). In this study, a statistically significant difference was found between the level of students' knowledge and their educational level ( $p=0.0001)$; so that, people with higher level of education had a higher level of awareness than those with lower level of education (Table 3). Data analysis and $\chi^{2}$ test revealed that there was a significant difference between the level of students' knowledge and the type of school $(p=0.0001)$. People attending public schools presented a higher level of awareness than those in private schools (Table 4).

\section{Discussion}

HIV is a serious medical phenomenon, but it is more important as a personal behavior and social and cultural phenomenon, with adolescents identified as at-risk population for HIV infection [3]. Daily, 6,000 people under the age of 25 are getting infected [12]. The importance and seriousness of the problem
Table 2. Level of knowledge of secondary high school students on AIDS by gender

\begin{tabular}{|c|c|c|}
\hline Variable mode & Frequency & Percentage \\
\hline \multicolumn{3}{|l|}{ Father's job } \\
\hline Laborer & 20 & 4 \\
\hline Employee & 227 & $4 / 45$ \\
\hline Freelance job & 173 & $6 / 34$ \\
\hline Other & 80 & 16 \\
\hline Total & 500 & 100 \\
\hline \multicolumn{3}{|l|}{ Mother's job } \\
\hline Employee & 168 & $6 / 33$ \\
\hline Freelance job & 35 & 7 \\
\hline Housewife & 231 & $2 / 46$ \\
\hline Other & 66 & $2 / 13$ \\
\hline Total & 500 & 100 \\
\hline \multicolumn{3}{|l|}{ Educational level } \\
\hline 10 & 254 & $8 / 50$ \\
\hline 11 & 229 & $8 / 45$ \\
\hline 12 & 17 & $4 / 3$ \\
\hline Total & 500 & 100 \\
\hline \multicolumn{3}{|l|}{ School type } \\
\hline Public school & 297 & $4 / 59$ \\
\hline Private school & 203 & $6 / 40$ \\
\hline Total & 500 & 100 \\
\hline \multicolumn{3}{|l|}{ Level of awareness } \\
\hline Insufficient & 11 & $2 / 2$ \\
\hline Medium & 142 & $4 / 28$ \\
\hline Sufficient & 347 & $4 / 69$ \\
\hline Total & 500 & 100 \\
\hline \multicolumn{3}{|l|}{ Attitude level } \\
\hline Negative & 1 & $2 / 0$ \\
\hline Neutral & 145 & 29 \\
\hline Positive & 354 & $8 / 70$ \\
\hline Total & 500 & 100 \\
\hline
\end{tabular}

of AIDS and its growing prevalence among adolescents contributed to the uprising of the "Healthy People by 2010 " program, which objectives are to increase the awareness of Iran's students about AIDS. Moreover, Iran has also emphasized the prevention and treatment of AIDS in its fourth plan of economic, social, and cultural development [13]. Our study showed that $69.4 \%$ of students had sufficient knowledge on AIDS. In this respect, the results of our study were consistent with those of Ranjbar et al. [11]. Also, 70.8\% of students had a positive attitude towards AIDS. Our study was in line with the study of Arab et al. [14], Ranjbar et al. [11], and Mazloomi et al. [3].

The present study showed that the percentage of people with sufficient knowledge was significantly higher in male stu- 
Table 3. Level of secondary high school students' knowledge on AIDS based on grade

\begin{tabular}{|c|c|c|c|c|c|c|}
\hline \multirow{2}{*}{ Parameter } & & \multicolumn{3}{|c|}{ Level of awareness } & \multirow{2}{*}{ Total } & \\
\hline & & Sufficient & Medium & Insufficient & & \\
\hline \multicolumn{7}{|l|}{ Grade } \\
\hline \multirow{2}{*}{10} & Frequency & 189 & 64 & 1 & 254 & \multirow{8}{*}{0.0001} \\
\hline & Percentage & 4.74 & 2.25 & 4.0 & 0.100 & \\
\hline \multirow{2}{*}{11} & Frequency & 142 & 77 & 10 & 229 & \\
\hline & Percentage & .062 & 6.33 & 4.4 & 0.100 & \\
\hline \multirow{2}{*}{12} & Frequency & 16 & 1 & 0 & 17 & \\
\hline & Percentage & 1.94 & 9.5 & 00. & 0.100 & \\
\hline \multirow{2}{*}{ Total } & Frequency & 347 & 142 & 11 & 500 & \\
\hline & Percentage & 4.69 & 4.28 & 2.2 & 0.100 & \\
\hline
\end{tabular}

*Based on $\chi^{2}$ test

Table 4. Level of secondary high school students' knowledge on AIDS based on school type

\begin{tabular}{|c|c|c|c|c|c|c|}
\hline \multirow{2}{*}{ Parameter } & & \multicolumn{3}{|c|}{ Level of awareness } & \multirow{2}{*}{ Total } & \\
\hline & & Insufficient & Medium & Sufficient & & \\
\hline \multicolumn{7}{|l|}{ School type } \\
\hline \multirow{2}{*}{ Public school } & Frequency & 1 & 66 & 230 & 297 & \multirow{6}{*}{0.0001} \\
\hline & Percentage & 0.3 & 22.2 & 77.4 & 100.0 & \\
\hline \multirow{2}{*}{ Private school } & Frequency & 10 & 76 & 117 & 203 & \\
\hline & Percentage & 4.9 & 37.4 & 57.4 & 100.0 & \\
\hline \multirow{2}{*}{ Total } & Frequency & 11 & 142 & 347 & 500 & \\
\hline & Percentage & 2.2 & 28.4 & 69.4 & 100.0 & \\
\hline
\end{tabular}

${ }^{*}$ Based on $\chi^{2}$ test

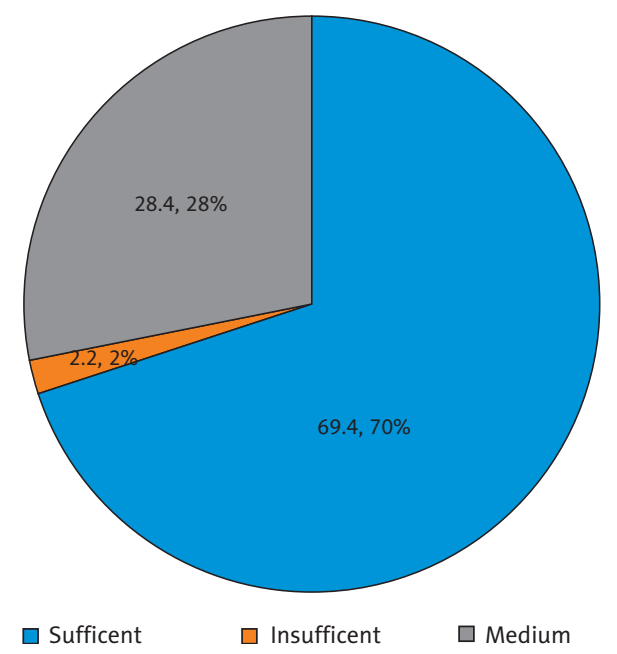

Figure 1. The level of knowledge of study subjects towards HIV

dents than in the female group. In this respect, our study was inconsistent with the study of Ranjbar et al. [11] and Mazloomi et al. [3], in which females were more aware than the male group. This difference may indicate a lack of proper education for female students in our study, which emphasizes the need for further improvement of the educational level of this at-risk group.

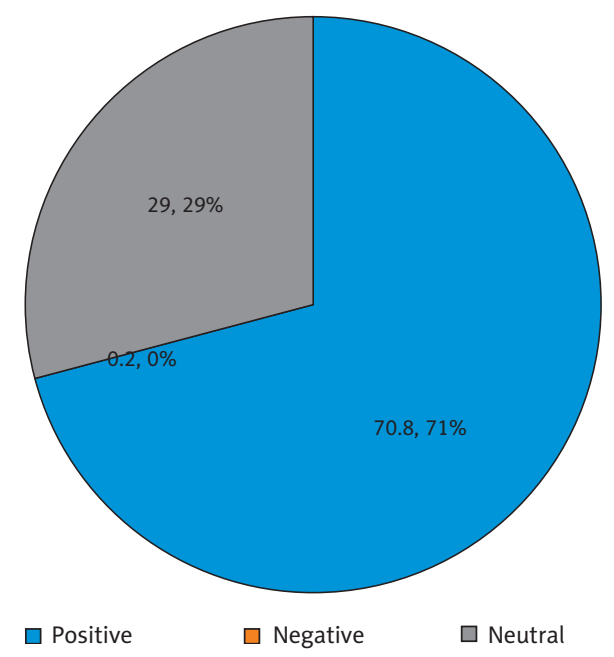

Figure 2. The level of attitude of study subjects towards HIV

Increasing the educational level means creating the capacity in students to teach higher-level science. Therefore, it is expected that with the increase in the level of education, students will be more knowledgeable. Therefore, according to this general rule, there was a statistically significant difference between the level of knowledge and level of educa- 
tion among high school students $(p=0.0001)$. The participants with higher educational level presented a higher level of awareness than those with lower educational level. In this respect, the results of our study were not in line with that of Ranjbar et al., in which there was a significant relationship between educational level and knowledge [11]. This result confirms our understanding of students' awareness, which suggests that as the educational level grows, the awareness should increase. Awareness and attitude are two close-related factors that unfortunately, sometimes does not receive much attention as needed in the educational aspect.

The type of school can also be an effective element in students' awareness. Exceptional talents schools, given the type, level, and quality of education, can increase the students' awareness and knowledge more than other schools. In this study, there was a significant difference between the level of students' knowledge and the type of school $(p=0.0001)$. People in public schools presented a higher level of awareness than responders from private schools. This discrepancy could be due to the selection of exceptional talents schools throughout the city as public schools and the greater number of students compared to the other schools under study.

In this study, we focused only on high school students in District 2, Rasht City, which has limited our study community. All information obtained from the students remained confidential. The results of the research were published in the form of group information, and the results were presented without mentioning names and personal details. However, the sample size was rather small. Basing the study on a larger sample size could have been generated more accurate results. The scope of discussions was one of the other limitations of this study. Since we did not have many years of experience of conducting researches and producing academic papers of large size, the scope and depth of discussions in the paper were compromised on many levels compared to the works of experienced scholars. It is recommended to pay more attention in educating about this disease in order to raise the awareness and attitude of different segments of society, especially in high-risk groups, such as students, to control the disease in the future.

\section{Conclusions}

The level of knowledge and attitude of the subjects was relatively good, although there were some uncertainties and misunderstandings about the most important ways of transmitting and not transmitting the disease as well as prevention methods. The results of this study and other related researches indicate the necessity of continuing formal and informal education, and efforts of educational, health, and cultural authorities in order to teach AIDS control and prevention methods. In addition, the results of this study can draw the attention of health authorities and social planners of the country to the factors, which influence students' knowledge and attitude. Failure to pay attention to these factors can affect the physical and mental health of students who are the future of this country.

\section{Acknowledgements}

This research was supported by vice chancellor of research and technology, Guilan University of Medical Sciences. We thank our colleagues from the Guilan University of Medical Sciences who provided insight and expertise that greatly assisted the research, although they may not agree with all of the interpretations/conclusions of this paper. We gratefully acknowledge the dedicated efforts of the investigators and coordinators participated in this study.

\section{Conflict of interest}

The authors declare no conflict of interest with respect to the research, authorship, and/or publication of this article.

\section{References}

1. Velayati AA, Bakayev V, Bahadori M, et al. Religious and cultural traits in HIV/AIDS epidemics in sub-Saharan Africa. Arch Iran Med 2007; 10: 486-497.

2. Gemeda TT, Gandile AU, Bikamo DS. HIV/AIDS knowledge, attitude and practice among Dilla University Students, Ethiopia. Afr J Reprod Health 2017; 21: 49-61.

3. Mazloomy SS, Baghianimoghadam MH. Knowledge and attitude about HIV/AIDS of schoolteachers in Yazd, Islamic Republic of Iran. East Mediterr Health J 2008; 14: 292-297.

4. Owusu SA. "Over my dead body": knowledge and attitude of children towards HIV and AIDS in the Cape Coast Metropolis of Ghana. Afr J Reprod Health 2015; 19: 63-72.

5. Chacko S, Kipp W, Laing L, Kabagambe G. Knowledge of and perceptions about sexually transmitted diseases and pregnancy: a qualitative study among adolescent students in Uganda. J Health Popul Nutr 2007; 25: 319-327.

6. Egbe CO, Dakum PS, Ekong E, et al. Depression, suicidality, and alcohol use disorder among people living with HIV/AIDS in Nigeria. BMC Public Health 2017; 17: 542.

7. Peltzer K, Pengpid S, Yung TKC, Aounallah-Skhiri H, Rehman R. Comparison of health risk behavior, awareness, and health benefit beliefs of health science and non-health science students: an international study. Nurs Health Sci 2016; 18: 180-187.

8. Li Y, Scott CS, Li L. Chinese nursing students' HIV/AIDS knowledge, attitudes, and practice intentions. Appl Nurs Res 2008; 21: 147-152.

9. Thomson C, Currie C, Todd J, Elton R. Changes in HIV/AIDS education, knowledge and attitudes among Scottish 15-16 year olds, 1990-1994: findings from the WHO: Health Behaviour in Schoolaged Children Study (HBSC). Health Educ Res 1999; 14: 357-370.

10. Friesen H, Danaya R, Doonar P, et al. Assessment of HIV/AIDS knowledge, attitudes and behaviour of high school students in $\mathrm{Pa}$ pua New Guinea. P N G Med J 1996; 39: 208-213.

11. Ranjbar H. Knowledge and attitudes of high school student about AIDS. Journal of Torbat Heydariyeh University of Medical Sciences 2008; 14: 51-56.

12. Grosso A, Busch S, Mothopeng T, et al. HIV risks and needs related to the Sustainable Development Goals among female sex workers who were commercially sexually exploited as children in Lesotho. J Int AIDS Soc 2018; 21 Suppl 1: e25042.

13. Bagheri Amiri F, Mostafavi E, Mirzazadeh A. HIV, HBV and HCV coinfection prevalence in Iran - a systematic review and metaanalysis. PLoS One 2016; 11: e0151946.

14. Arabi M, Rakhshi M, Heidarzadeh M, Ghahramanian A. Knowledge and attitude of female high school students in relation to AIDS in Bonab. J Holist Nurs Midwifery 2013; 23: 45-53. 